\title{
The Graphical Index of Pain: a new web-based method for high-throughput screening of pain
}

\author{
Ólöf Anna Steingrímsdóttir ${ }^{a, \star}$, Bo Engdahl ${ }^{\mathrm{a}}$, Per Hansson ${ }^{\mathrm{b}, \mathrm{c}}$, Audun Stubhaug $^{\mathrm{b}, \mathrm{d}}$, Christopher Sivert Nielsen ${ }^{\mathrm{a}, \mathrm{b}}$
}

\begin{abstract}
This article is the first to present the Graphical Index of Pain (GRIP), a new user-friendly web-based method for high-throughput screening of pain. The long-term goal of the method is to improve global standardization of pain measurements. GRIP consists of a hierarchical body map with 10 first-tier body regions, and a second tier with multiple pain loci (167 among men, 168 among women), which provides detailed information about pain location and distribution. Follow-up questions for first-tier regions include the following pain characteristics: onset, episode frequency, episode duration (including constant pain), intensity, bothering, depth of pain, and effects on sleep and daily activities. The first implementation of GRIP was in the Tromsø Study (2015-2016), a population-based study of adults aged 40 to 99 years. In total, 21,083 individuals participated in the study, and 96\% ( $\mathrm{n}=20,263$; age 40-96 years) completed GRIP. Pain intensity at first-tier regions and pain location and distribution at second-tier regions are in this article presented by sex-stratified customized heat maps showing large sex difference. Mean time to mark the first- and secondtier regions was 74 seconds. In conclusion, GRIP allows for high-resolution assessment and presentation of pain location and distribution with minimal use of time.
\end{abstract}

Key Words: Pain location, Pain distribution, Pain characteristics, Methodology, Assessment

\section{Introduction}

Population statistics show that pain has considerable societal impact and is a leading cause of poor health and disability. ${ }^{6,17}$ But the accuracy of the statistics depends on the methods used to collect data. A meta-analysis of population-based studies of chronic pain prevalence found estimates that ranged from $9 \%$ to $64 \%$, and it is likely that methodological factors are strongly involved in the disparities between these studies. For example, it is rare that 2 studies use the same criteria for defining chronic pain criteria, and estimates showed that interview survey methods of collecting data yielded higher rates of pain reporting than questionnaire survey methods. ${ }^{15}$ The findings from the meta-

\footnotetext{
Sponsorships or competing interests that may be relevant to content are disclosed at the end of this article.

a Division of Mental and Physical Health, Norwegian Institute of Public Health, Oslo, Norway, ${ }^{b}$ Division of Emergencies and Critical Care, Department of Pain Management and Research, Oslo University Hospital, Oslo, Norway, ${ }^{c}$ Department of Molecular Medicine and Surgery, Karolinska Institutet, Stockholm, Sweden,

a Institute of Clinical Medicine, Faculty of Medicine, University of Oslo, Oslo, Norway ${ }^{*}$ Corresponding author. Address: Division of Mental and Physical Health, Norwegian Institute of Public Health, P.O. Box 4404 Nydalen, NO-0403 Oslo, Norway. Tel.: +47 210782 86; fax: +47 210781 46. E-mail address: Olof.Anna.Steingrimsdottir@fhi.no (Ó.A. Steingrímsdóttir).

Supplemental digital content is available for this article. Direct URL citations appear in the printed text and are provided in the HTML and PDF versions of this article on the journal's Web site (www. painjournalonline.com).

PAIN 161 (2020) 2255-2262

Copyright (C) 2020 The Author(s). Published by Wolters Kluwer Health, Inc. on behalf of the International Association for the Study of Pain. This is an open access article distributed under the terms of the Creative Commons Attribution-Non CommercialNo Derivatives License 4.0 (CCBY-NC-ND), where it is permissible to download and share the work provided it is properly cited. The work cannot be changed in any way or used commercially without permission from the journal.

http://dx.doi.org/10.1097/j.pain.0000000000001899
}

analysis highlight some of the methodological problems that may influence results and the need for standardization.

Despite effort to improve pain measures, the development of methodologies for assessing pain in a standardized manner is still insufficient. Besides huge variation in operational definitions, ${ }^{15}$ there is no consensus on other factors that might represent or capture features of pain phenotypes. For example, a variety of paper and pencil questionnaires, some of them containing body manikins, have for decades been used to map pain characteristics, pain location, and pain distribution. In addition to lack of consensus about pain characteristics, the paper body manikins often vary, sometimes offering one view (front or back) or 2 views (front and back) and sometimes with or without predivided body regions that the respondent shades or marks the pain location. The variations in these pain location measures obviously can yield different conclusions about the pain experienced by the respondent.

More recently, electronic technologies have opened up the possibility of standardizing pain assessment by using computeraided methods. Nevertheless, well-validated and standardized digital instruments for assessing pain remain scarce. Interestingly, electronic tools seem to capture information about pain that is equivalent to paper and pencil assessments. ${ }^{1,3,5,9,10,14}$

Computer-based pain location measures (electronic manikins) are currently available. However, many are simply a copy of the different predivided paper and pencil manikins and do not use data programming possibilities, such as hierarchical layers, to create more efficient and clinically meaningful instruments. Advanced digital pain drawing tools, where the respondents shade a blank manikin, are often clinically meaningful, but they can be influenced by the drawing skills of respondents and may be difficult to use in large-scale research. In addition, some of the computer-based tools for assessing pain location through electronic manikins are proprietary, which can limit their accessibility. 
There is a growing consensus among researchers and clinicians on the need for standardization in the assessment and reporting of pain both within and across countries. There is also heightened recognition that standardized measurement tools should be easily accessible, cheap in use, time-efficient, easily understandable, and as minimally dependent on cultural differences, language, and reading or drawing skills as possible. We considered all the above-mentioned issues when we designed and developed a new hierarchical digital instrument for high-throughput screening of pain, the Graphical Index of Pain (GRIP). GRIP was developed to provide detailed information about pain distribution based on clinically meaningful predefined body areas. It should be easy to integrate with other digital instruments and to link to relevant questions that the community of pain researchers and clinicians can agree upon. Our intention was to produce an instrument that could not only be used for high-throughput pain assessment in large-scale studies but also for screening purposes in clinical pain management, to pinpoint distribution of pain for further analysis during history taking and bedside examination.

The goal of this article is to describe this instrument and to illustrate its potential, using data from a population-based Norwegian survey (the Tromsø Study). The ultimate goal of developing GRIP is to improve global standardization of pain measurements.

\section{Methods}

\subsection{Tromsø Study}

The Tromsø Study is a population-based survey performed every 6th to 7th year. In total, 7 waves have been conducted (from 1974 to 2016). For detailed information about the survey and the first 6 waves, see Refs. 4 and 8 . The data presented here were collected as part of the seventh wave of the Troms $\varnothing$ Study (Tromsø 7; 20152016). All residents in the Tromsø Municipality of Northern Norway, 40 years and older, were invited by postal letter to participate ( $\mathrm{n}=$ 32,591; 16,052 men and 16,539 women; age 40-99 years). The survey included sampling of clinical measurements at a research station, biological specimens, a paper and pencil questionnaire on diet, and electronic questionnaires covering demographic, lifestyle and health measures, and the GRIP. Participants could fill in data before their first visit at the research station, or at the station where research technicians provided additional information and assistance when needed. At the research station, the participants could choose to provide data using desktop computer, notepad, or his or her own mobile device.

The Troms $\varnothing$ Study has been approved by the Norwegian Data Protection Authority (14/01463-8/CGN) and by the Regional Committee for Medical and Health Research Ethics (2009/2536/ REC North). The participants gave their informed consent.

\subsection{Body map}

The GRIP body map has 10 first-tier body regions (Fig. 1). Marked first-tier regions are then magnified into anatomical sites at a second tier (167 loci among men and 168 loci among women) (Fig. 2). A certified medical illustrator drew all the images included in GRIP. The chosen colour palette is distinguishable for colourblind persons. Although GRIP unquestionably is not to be used as a stand-alone diagnostic tool, some of the outlined body regions coincide with common distributions of the peripheral nervous system and, if indicated by the patient, may serve as an adjunct in the full-blown diagnostic workup of a suspected lesion or disease of the somatosensory nervous system, eg, a neurological lesion or disease as a potential underlying cause of a pain in the acral distribution of dermatomes C6 to C8 in the hand and L5 and S1 in the foot, as depicted in the second-tier body regions in Figure 2. Also the 3 branches of the trigeminal nerve are roughly outlined, but to some extent as a compromise with body regions such as the orbital areas, which are also included in the trigeminal innervation territory (Fig. 2).

\subsection{Translation and validation}

All instructions and questions in GRIP were put in Norwegian. The translation from Norwegian to English was made by a certified translator. Back translation is in process. Validated translation and back translation to other languages and necessary validation

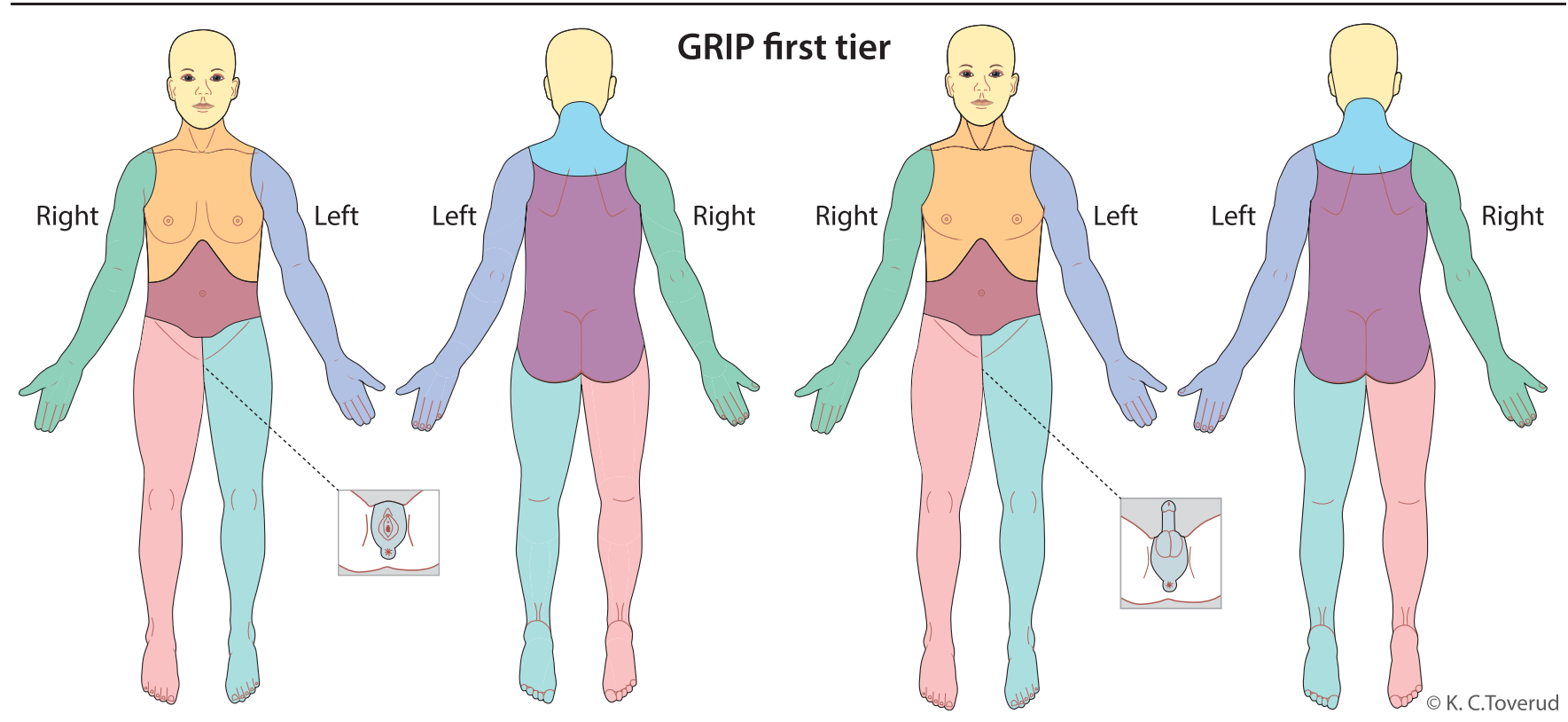

Figure 1. The Graphical Index of Pain (GRIP): 10 first-tier body regions for women (left panel) and men (right panel). 


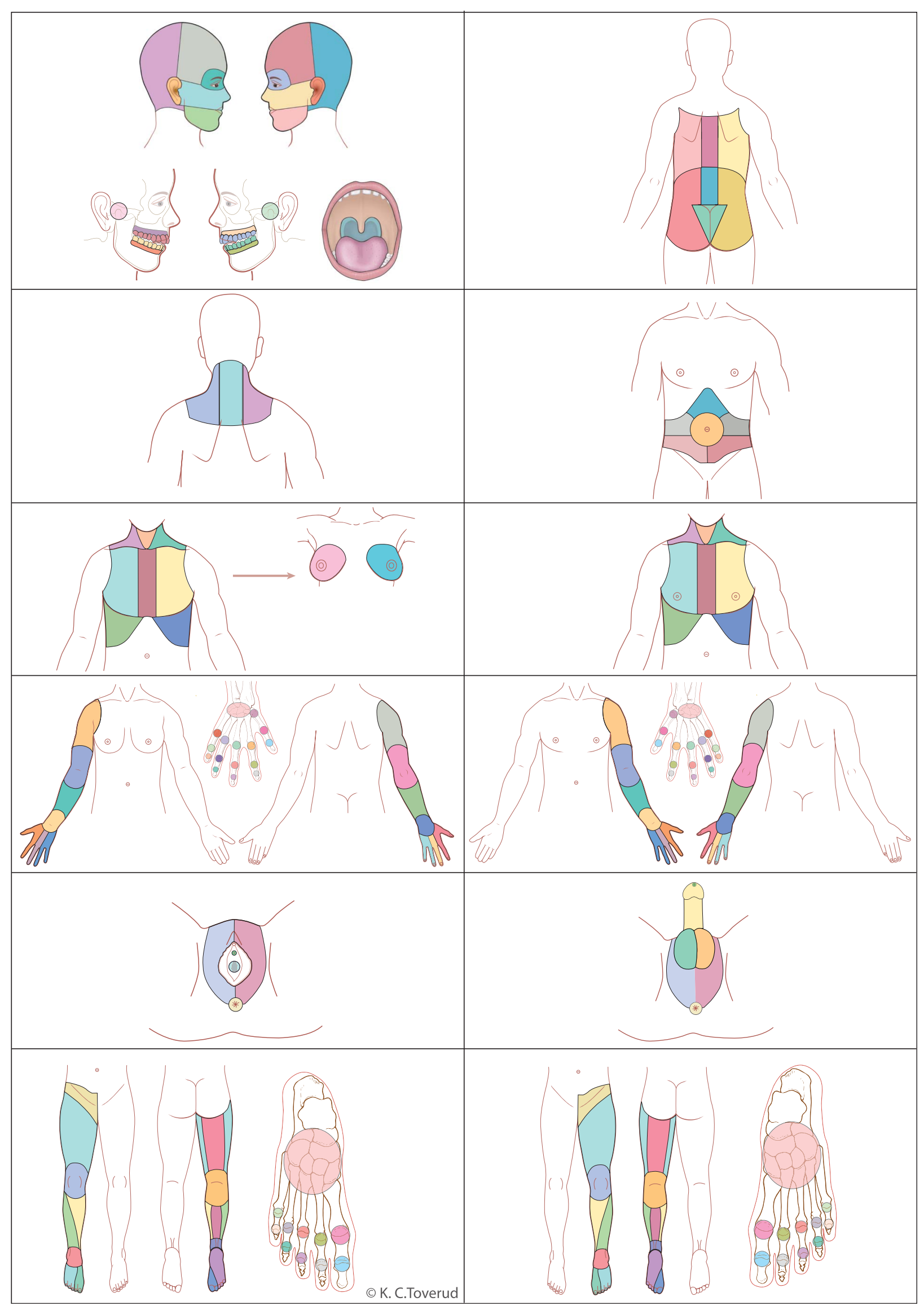

Figure 2. The Graphical Index of Pain (GRIP): Second-tier body regions ( $n=167$ for men, 168 for women). 
of instructions and questions used in GRIP have yet to be completed.

\subsection{Entry instructions}

The first page in GRIP included the following instructions: "On the next pages, we ask you about pain you have had during the last 4 weeks. Include all types of pain, both superficial and deep (in the chest, mouth, abdomen, skin, muscles and joints, genitals, urethra, etc). Do not include transient, brief pain."

Women were instructed not to include menstrual pain (this was covered in a separate questionnaire). Respondents were asked to choose between a woman's or a man's body.

On the second page, respondents were asked to mark their pain locations: "Click on all areas where you have had pain during the last 4 weeks. Even if you have only had pain in part of an area, you must still mark the area as a whole. You must indicate where you have had pain, not where you think the cause of the pain lies. You can unmark an area by clicking on it again. If you have not had pain during the last 4 weeks, continue to the next page."

If a respondent did not mark any area, a text box appeared with the following questions: "You have indicated that you have not had any pain during the last 4 weeks. Is this correct? The respondent could choose between 3 alternatives: "It is correct, I have not had pain," "No, take me back to the picture," and "I do not want to answer questions about pain."

See also Appendix I and Appendix II for case examples (available as supplemental digital content at http://links.Iww.com/ PAIN/B4).

\subsection{Questions about pain characteristics}

For each of the marked first-tier regions, the respondent was asked to rate pain onset, episode frequency, episode duration (including constant pain without pause), pain intensity, bothering, and depth of pain (superficial, deep, or both). If the respondent had experienced more than one type of pain within a first-tier region, he or she was asked to rate the pain that had bothered him or her the most.

Onset of pain was assessed with the response options less than 4 weeks, 1 to 2, 3 to 5, 6 to 11 months, 1 to 2, 3 to 5 years, and more than 5 years. Participants reporting more than 5 years in pain were asked to report about their age at pain onset. Episode frequency was reported on a 29-point numeric rating scale (NRS; 0-28 days) (Question: During the last 4 weeks: How many days have you had the pain?). Episode duration within the last 4 weeks (Question: About how much of the day have you usually had the pain? [Only count the time when you are awake]) was assessed with the response options less than 1, 1 to 2, 3 to 6, 7 to 10 hours, more than 10 hours, or all the time, without pause. Pain intensity the last 4 weeks was rated on a NRS with the anchors "No pain" $(0)$ and "The strongest imaginable pain" (10) by answering the question "How strong has the pain usually been?" Similarly, bothering the last 4 weeks was rated on a NRS with the anchors "No bother" (0) and "The greatest imaginable bother" (10), in response to the question "How much has the pain usually bothered you?" Depth of pain was assessed by the question "Where is the pain located?" using the response options "Superficially," "Deeply," "Both of the above," or "I don't know." Participants who reported pain in the lower back were also asked about radiating leg pain (yes/no), the distance of the radiation (hip/buttocks; thigh/knee; lower leg/ankle; heel/sole of the foot; instep/toes), and those with pain radiating to the heel, foot sole, or toes where asked about altered sensation in the painful foot (eg, numbness and tingling) (yes/no).

Once the participants had reported on pain characteristics related to the afflicted first-tier regions, they were asked about effects of overall pain (across all regions) on sleep quality and daily activities using NRS. Sleep quality was assessed by the question "To what extent does the pain affect your sleep?" (NRS: 0 = "Not at all," 10 = "Impossible to sleep"). Effects on daily activity were assessed by the question "To what extent does the pain prevent you from performing your daily activities?" (0 = "Not at all," $10=$ "Can't do anything").

An updated version of GRIP uses visual analogue scale instead of NRS (see Appendix I, available at http://links.Iww.com/ PAIN/B4).

\subsection{Tiredness and fatigue}

Fatigue was assessed by the Chalder Fatigue Scale. ${ }^{2,11}$ The Norwegian version of the Chalder Fatigue Scale includes 2 questions about tiredness, each of them with 4 response options, in addition to the 11 items published by Chalder et al. in 1993. ${ }^{2}$

\subsection{Heat maps}

To gain a better overview and discrimination between different layers of information from GRIP, we created customized heat maps to present the complexity of the collected data and to visualize results from the body map. Heat map is a graphical presentation of data where different values are represented in spectrum of colours. It is a helpful tool to get an overview over large data at a glance and efficient in visualizing trends. In GRIP, we combine information about pain characteristics and

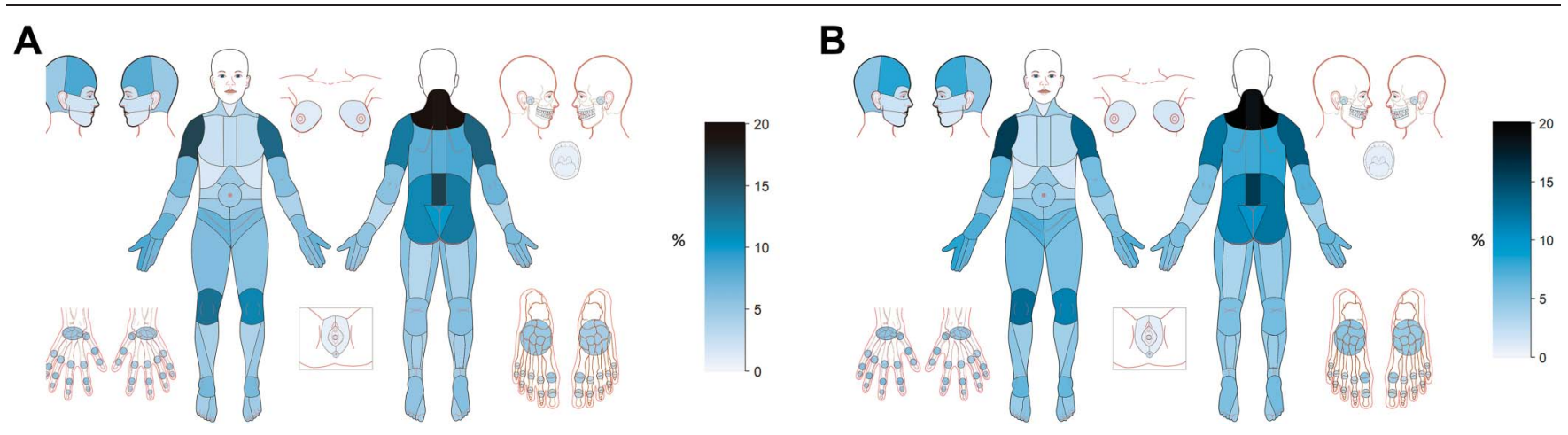

Figure 3. Prevalence of pain within the last 4 weeks in a general population reported on the Graphical Index of Pain (GRIP; second tier). (A) Women, 168 loci, $\mathrm{n}=$ 9527). (B) Men, 167 loci, $\mathrm{n}=8845)$. Data from the Tromsø Study 2015 to 2016. 


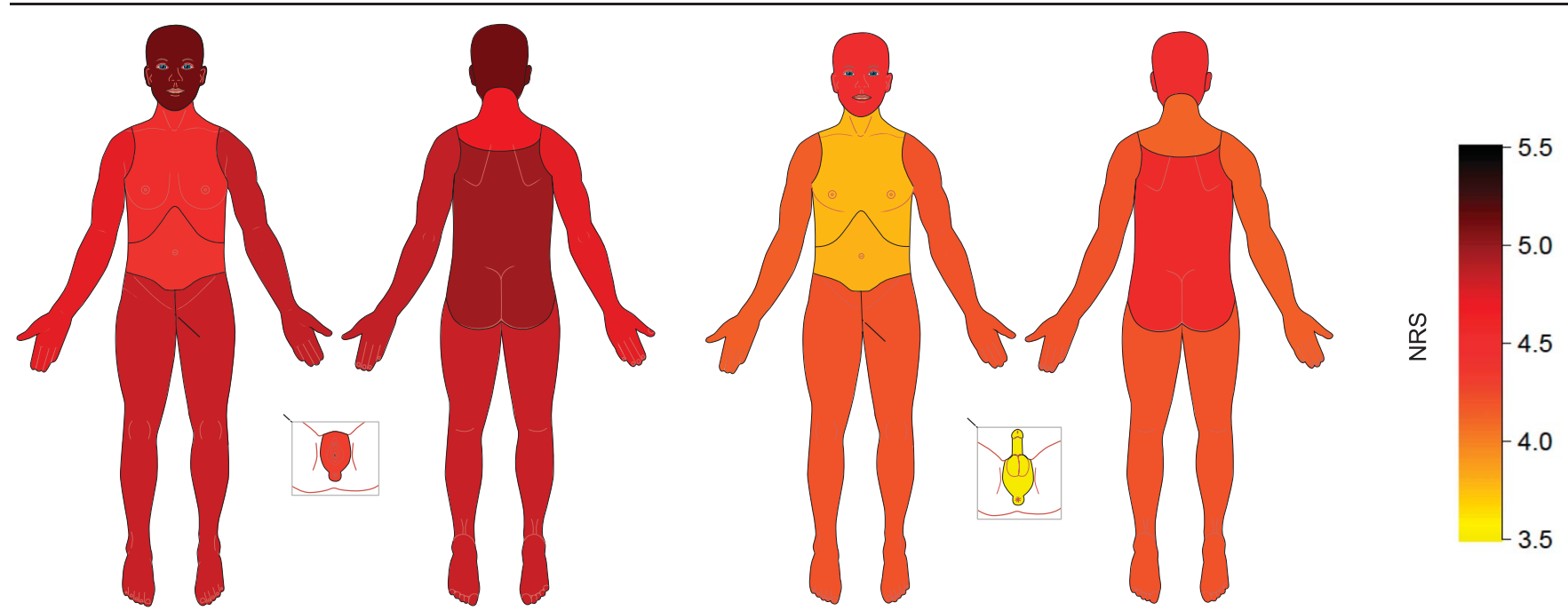

Figure 4. Pain intensity within the last 4 weeks in each of the painful first-tier regions (duration $\geq 6$ months) reported on the Graphical Index of Pain (GRIP) for women (left panel) and men (right panel). Participants were asked to indicate how strong the pain usually was on a numeric rating scale (NRS), with the anchors No pain (0) and The strongest imaginable pain (10). Number of cases ranges from 244 to 2456 in women (left panel), and 280 to 1321 in men (right panel) dependent on body region. Data from the Tromsø Study 2015 to 2016.

pain distribution by using different spectrum of colours to visualize different findings. For example, we use yellow/black spectrum for pain intensity and white/blue spectrum for pain prevalence.

The heat maps were created in R (version 3.5.2; https://www.rproject.org) with functions for manipulating vector graphics to colour loci of the GRIP images, based on values in the input data matrix.

\subsection{Statistics}

Several examples of descriptive statistical measures (mean or percentages) were calculated to give some insight to the potential of GRIP data (in numbers or in heat maps).
Mean time used to mark either the first and second tier of GRIP (the graphical section) or for the full battery, including questions on pain characteristics, sleep, daily activities, and fatigue, was calculated for respondents using more than 0 second and less than 3600 seconds to complete GRIP (>3599 seconds defined as program failure).

\section{Results}

A total of 21,083 persons (64.7\%) participated in the Troms $\varnothing 7$. Of those, $96 \%$ ( $n=20,263)$ mapped their pain details in GRIP (9624 men, 10,639 women; age 40-96). Because of delayed start-up of GRIP, we have $4 \%$ missing participants at the beginning of the study ( $n=820$; 385 men, 435 women; age 40-99 years).

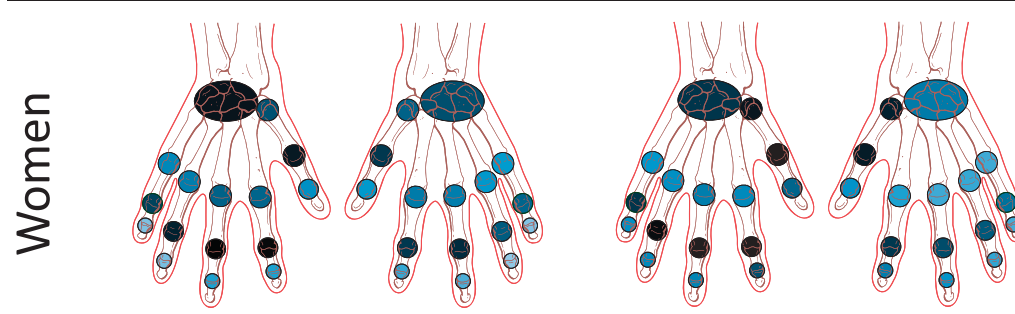

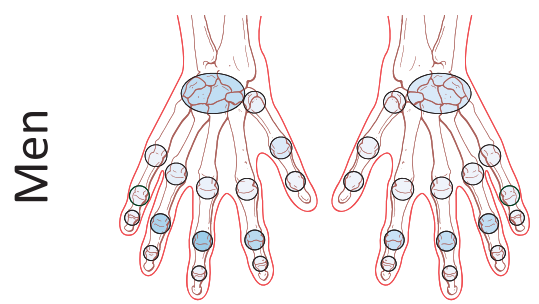

$40-54$ years

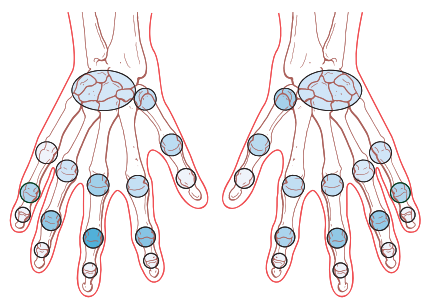

$55-69$ years
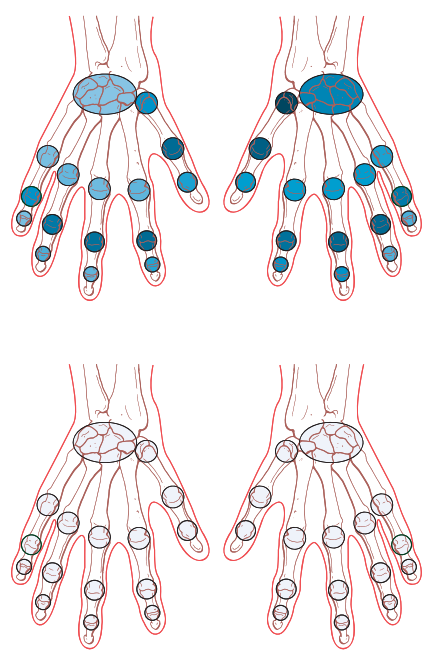

$\%$

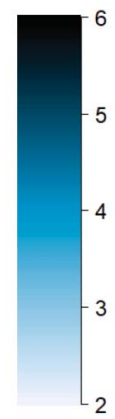

\section{$70-96$ years}

Figure 5. Pain prevalence in the right hand during the last 4 weeks in a general population of women and men (3 age groups). Reported on the Graphical Index of Pain (GRIP). Data from the Tromsø Study (2015 to 2016). 

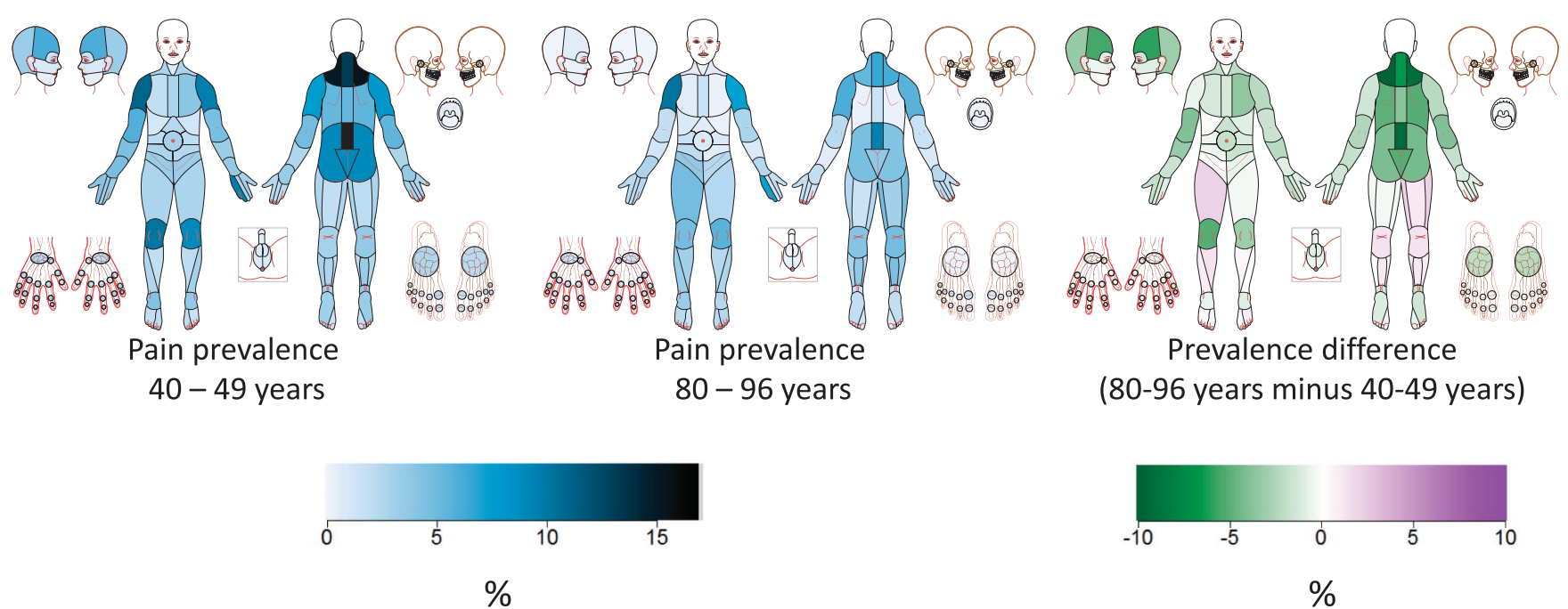

$\%$

96 years). Reported on the

Figure 6. Pain prevalence and prevalence difference during the last 4 weeks Graphical Index of Pain (GRIP). Data from the Tromsø Study (2015 to 2016).

Figure 3 illustrates the distribution of pain in the second tier and sex differences. For both sexes, the loci with highest 4-week prevalence are the neck, shoulders, knees, and lower back. Figure 4 shows that women report higher pain intensity than men.

Figure 5 demonstrates pain distribution in hand over 3 age groups, women vs men, and shows that the reported pain is for both sexes higher in younger than older age groups. This is further explored in Figure 6 where we compare pain prevalence in 40 to 49 years old men with those aged 80 to 96 years. Also here we find higher pain prevalence among the younger ones in most body regions.

Case examples of localized pain vs widespread pain are given in Figures 7 and 8.

Mean time used to mark the first- and second-tier regions was 74 seconds. Mean time was 6:31 minutes for finishing the first and second tier, all the additional questions and the Chalder's Fatigue Scale. Sixty-six percent of the participants used desktop or portable computer to fill in GRIP $(n=13,425)$, whereas others used tablet or mobile phone $(n=6837)$.

\section{Discussion}

Body manikins are commonly used to capture pain distribution, while written questions are still an important source for assessing pain characteristics. GRIP is a flexible approach that optimizes both approaches. The findings from the large population-based Tromsø Study demonstrate the rich and detailed information GRIP provided from participants in adulthood and old age. The study also supports the timesaving aspects of the method for gathering large scale detailed information, compared with questionnaires and manikins without hierarchical layers.

\subsection{Manikins, written questions, and delivery modes}

A Cochrane review from 2015 included a broad spectrum of trials and outcomes to compare delivery of self-administered questionnaires using smartphone or tablet apps with any other delivery mode. ${ }^{12}$ The review did not find statistically significant differences in different measures on data equivalence such as mean overall scores, but data

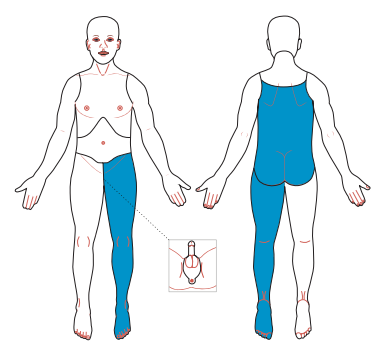

Afflicted body regions (First tier)

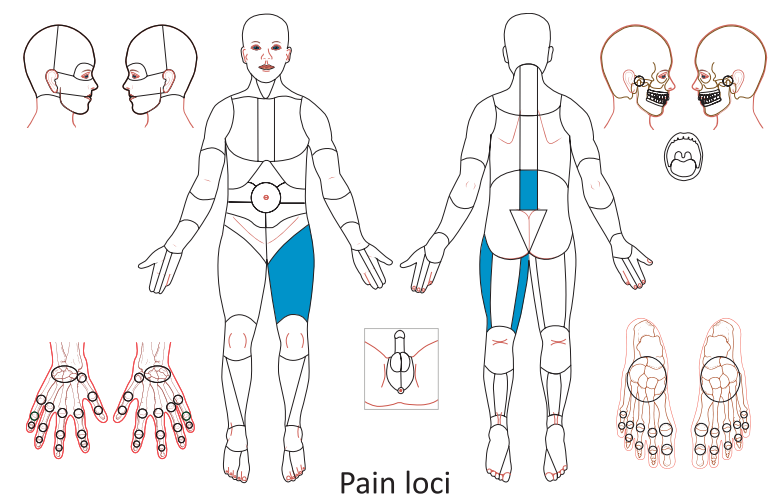

(Second tier)

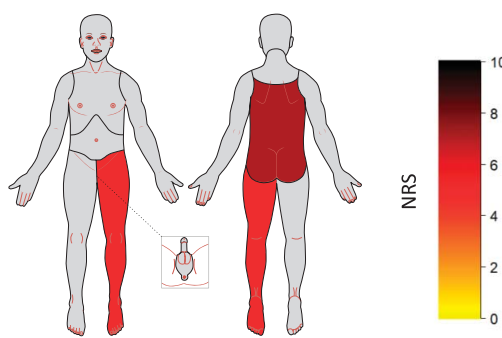

Pain intensity (Afflicted first-tier regions)

Figure 7. A case example from epidemiology: A man reporting back and leg pain within the last 4 weeks with onset 15 years ago. Daily deep pain, with more than 7 to 10-hour duration a day. The pain characteristics were rated for the marked first-tier regions. Numeric rating scale (NRS) had the anchors: "No pain" (0) and "The strongest imaginable pain" (10). Data from the Tromsø Study 2015 to 2016. 


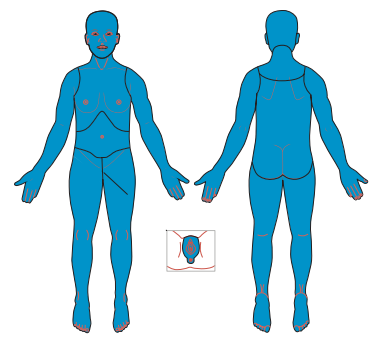

Afflicted body regions (First tier)

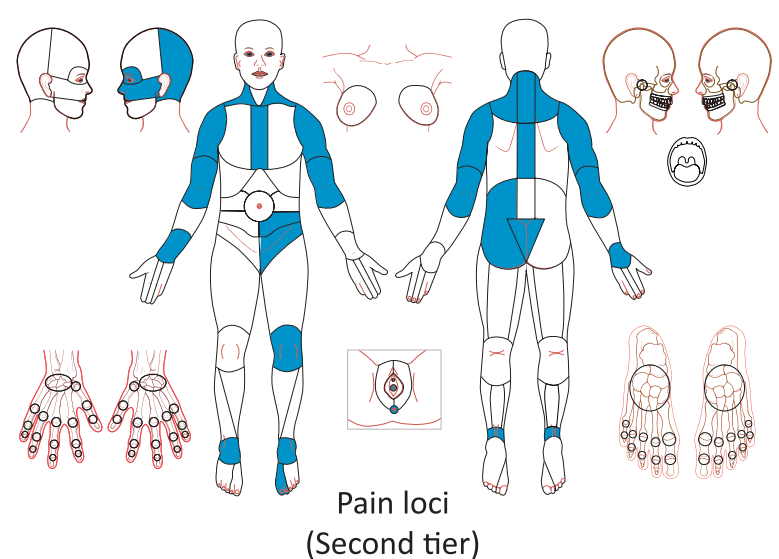

(Second tier)

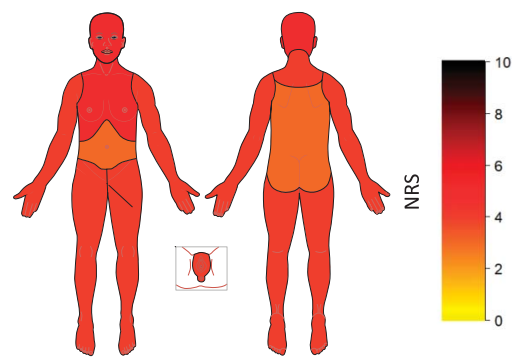

Pain intensity (Afflicted first-tier regions)

Figure 8. A case example from epidemiology: A woman reporting widespread pain within the last 4 weeks. Pain characteristics vary across regions as follows: Onset from 3 to 18 years back in time; frequency from 10 to 28 days the last 4 weeks; Episode duration from 7 to 10 hours to "All the time, without pause." Pain characteristics were rated for the marked first-tier regions. Numeric rating scale (NRS) had the anchors: "No pain” (0) and "The strongest imaginable pain" (10). Data from the Troms $\varnothing$ Study 2015 to 2016.

completeness and adherence were better for apps than for paper and pencil. The Cochrane review did not include apps allowing for data entry in the form of pictures. ${ }^{12}$ However, van den Hoven et al. (2010) compared musculoskeletal pain prevalence data from manikins with data from written questions and concluded that the 2 approaches yield similar findings. ${ }^{16}$ Pain location in populationbased surveys seem to be captured in a comparable fashion on manikins administrated online vs paper and pencil, ${ }^{9}$ and pain intensity measured by visual analogue scale seems to be similarly captured across administration modes. ${ }^{10,13}$ Findings indicate that the response rate is similar in paper and pencil and online surveys, but with faster available data with online administration. ${ }^{7}$ To summarize, the different approaches are likely to give comparable results given that other important methodological factors are standardized.

\subsection{Strengths and limitations}

One of the core strengths of GRIP is its time efficiency. GRIP provides comprehensive information obtained in just seconds or a few minutes for most people, and the data are promptly available due to the electronic delivery mode. Such high-throughput screening of pain is important in both research and practice. GRIP emphasizes graphical presentation and pain distribution details and hence reasonably minimizes linguistic, cultural, and educational influence in reporting. To reduce the linguistic differences, we created images of regions and loci without using identifying tags. All the first-tier body regions follow this rule. The pain loci in the second tier are also without identifying tags, except for some of the multiple pain loci (ie, "teeth, gum, jaw joint," "lips, palate/oral cavity, tongue, throat," "joints of the left hand," "joints of the right hand," "joints of the left foot," "joints of the right foot," "urethra, anus" for men, and "urethra, anus, vagina" for women). GRIP has also images of regions and loci with colour palette adapted for colour blindness, for example, different grades of blue, green, yellow, and red, at the same time, as we avoided implementing human skin colours. Furthermore, educational differences in participating and reporting may be associated with illiteracy, dyslexia, or other reading disorders. Future versions of GRIP will include functionality that allows for converting text to speech by tapping audio links.

The high number of loci in the second tier limited our ability to use questions to report on pain characteristics in each of the second-tier loci. In the Troms $\varnothing$ Study, we asked respondents to only report on pain characteristics from the first-tier body regions, a total of 10 regions. Therefore, it was for example, not possible to distinguish between reports on characteristics of complaints from the hand and the elbow. In further development, we plan to add the possibility for respondents to report in more detail on second-tier loci in specialized applications, for example, from specific regions in the head.

The Tromsø Study is well suited to show the potential of GRIP. This large population-based study has a participation rate that is higher than is customary for surveys today, and it includes persons whose age is up in the nineties. According to the research technicians who assisted at the research station, age did not seem to be a hindrance for completing GRIP. The rich data allow for testing of multiple research hypothesis, and the data presented in this article demonstrate that the customized heat maps is an effective method to display differences between groups. Although the goal of this article was to present a new research tool and not to answer specific research questions, the heat maps based on the data from the Troms $\varnothing$ Study give an accessible overview of, eg, sex and age differences in pain distribution and pain characteristics.

Additional research is needed to more definitively test and refine the psychometric properties of GRIP in different settings in research and clinical practice. Findings from this work might initiate changes on GRIP, resulting in GRIP version 2 or higher. The user-friendliness of GRIP will be further tested out in upcoming projects.

\subsection{Dissemination}

The source code is distributed through github licensed open source under GNU GENERAL PUBLIC LICENSE (https://github.com/ unioslo/kroppskart). The applications are programmed in Javascript with React Native, and it is designed to post data through SSL to a 3-party secure storage. The application can run on any linux server, and it is possible to modify it to store in a local database. Application to run on other type of servers is under development. R-functions integrating heat maps with the GRIP images are distributed through the github licensed open source under GNU GENERAL PUBLIC LICENSE https://github.com/bolarsengdahl/GRIP-Heatmap.

\subsection{Conclusion}

GRIP gives detailed information about pain distribution and characteristics in a general population with minimal use of time. Heat maps based on data from Tromsø 7 gives revealing visual overview of sex differences in pain prevalence, distribution, and intensity. 


\section{Conflict of interest statement}

The authors have no conflicts of interest to declare.

\section{Acknowledgments}

Heat maps were based on the GRIP images. The GRIP drawings were created by Kari C. Toverud, certified medical illustrator, in collaboration with the authors. The programming of GRIP was performed by special advisers Terje Merøy and Bjørn-Ole Johannesen at the Norwegian Centre for Research Data, University of Bergen. Further development of GRIP is performed in co-operation with Dagfinn Bergsager and his co-workers at the Web Application Development Group, Centre for Information Technology, University of Oslo. Funding was provided by Oslo University Hospital, the Norwegian Institute of Public Health, and the Norwegian Fund for Post-Graduate Training in Physiotherapy. Finally, the authors thank all participants and coworkers in the Tromsø study.

\section{Appendix A. Supplemental digital content}

Supplemental digital content associated with this article can be found online at http://links.Iww.com/PAIN/B4.

\section{Article history:}

Received 2 July 2019

Received in revised form 3 April 2020

Accepted 19 April 2020

Available online 24 April 2020

\section{References}

[1] Boudreau SA, Badsberg S, Christensen SW, Egsgaard LL. Digital pain drawings: assessing touch-screen technology and $3 \mathrm{D}$ body schemas. Clin J Pain 2016;32:139-45.

[2] Chalder T, Berelowitz G, Pawlikowska T, Watts L, Wessely S, Wright D, Wallace EP. Development of a fatigue scale. J Psychosom Res 1993;37:147-53.

[3] Cook AJ, Roberts DA, Henderson MD, Van Winkle LC, Chastain DC, Hamill-Ruth RJ. Electronic pain questionnaires: a randomized, crossover comparison with paper questionnaires for chronic pain assessment. PAIN 2004;110:310-17.

[4] Eggen AE, Mathiesen EB, Wilsgaard T, Jacobsen BK, Njolstad I. The sixth survey of the Tromso Study (Tromso 6) in 2007-08: collaborative research in the interface between clinical medicine and epidemiology: study objectives, design, data collection procedures, and attendance in a multipurpose population-based health survey. Scand J Public Health 2013;41:65-80.

[5] Egsgaard LL, Christensen TS, Petersen IM, Bronnum DS, Boudreau SA. Do gender-specific and high-resolution three dimensional body charts facilitate the communication of pain for women? A quantitative and qualitative study. JMIR Hum Factors 2016;3:e19.

[6] Goldberg DS, McGee SJ. Pain as a global public health priority. BMC Public Health 2011;11:770.

[7] Horevoorts NJ, Vissers PA, Mols F, Thong MS, van de Poll-Franse LV. Response rates for patient-reported outcomes using web-based versus paper questionnaires: comparison of two invitational methods in older colorectal cancer patients. J Med Internet Res 2015;17:e111.

[8] Jacobsen BK, Eggen AE, Mathiesen EB, Wilsgaard T, Njolstad I. Cohort profile: the Tromso Study. Int J Epidemiol 2012;41:961-7.

[9] Jones GT, Kyabaggu R, Marais D, Macfarlane GJ. Reproducibility of pain manikins: a comparison of paper versus online questionnaires. Br J Pain 2013;7:130-7.

[10] Junker U, Freynhagen R, Langler K, Gockel U, Schmidt U, Tolle TR, Baron R, Kohlmann T. Paper versus electronic rating scales for pain assessment: a prospective, randomised, cross-over validation study with 200 chronic pain patients. Curr Med Res Opin 2008;24:1797-806.

[11] Loge JH, Ekeberg O, Kaasa S. Fatigue in the general Norwegian population: normative data and associations. J Psychosom Res 1998;45:53-65.

[12] Marcano Belisario JS, Jamsek J, Huckvale K, O'Donoghue J, Morrison CP, Car J. Comparison of self-administered survey questionnaire responses collected using mobile apps versus other methods. Cochrane Database Syst Rev 2015:MR000042.
[13] Mulhern B, O'Gorman H, Rotherham N, Brazier J. Comparing the measurement equivalence of EQ-5D-5L across different modes of administration. Health Qual Life Outcomes 2015;13:191.

[14] Southerst D, Stupar M, Cote P, Mior S, Stern P. The reliability of measuring pain distribution and location using body pain diagrams in patients with acute whiplash-associated disorders. J Manipulative Physiol Ther 2013;36:395-402.

[15] Steingrimsdottir OA, Landmark T, Macfarlane GJ, Nielsen CS. Defining chronic pain in epidemiological studies: a systematic review and metaanalysis. PAIN 2017;158:2092-107.

[16] van den Hoven LHJ, Gorter KJ, Picavet HSJ. Measuring musculoskeletal pain by questionnaires: the manikin versus written questions. Eur J Pain 2010;14:335-8.

[17] Vos T, Flaxman AD, Naghavi M, Lozano R, Michaud C, Ezzati M, Shibuya K, Salomon JA, Abdalla S, Aboyans V, Abraham J, Ackerman I, Aggarwal R, Ahn SY, Ali MK, Alvarado M, Anderson HR, Anderson LM, Andrews KG, Atkinson C, Baddour LM, Bahalim AN, Barker-Collo S, Barrero LH, Bartels DH, Basanez MG, Baxter A, Bell ML, Benjamin EJ, Bennett D, Bernabe E, Bhalla K, Bhandari B, Bikbov B, Bin Abdulhak A, Birbeck G, Black JA, Blencowe H, Blore JD, Blyth F, Bolliger I, Bonaventure A, Boufous S, Bourne R, Boussinesq M, Braithwaite T, Brayne C, Bridgett L, Brooker S, Brooks P, Brugha TS, Bryan-Hancock C, Bucello C, Buchbinder R, Buckle G, Budke CM, Burch M, Burney P, Burstein R, Calabria B, Campbell B, Canter CE, Carabin H, Carapetis J, Carmona L, Cella C, Charlson F, Chen H, Cheng AT, Chou D, Chugh SS, Coffeng LE, Colan SD, Colquhoun S, Colson KE, Condon J, Connor MD, Cooper LT, Corriere M, Cortinovis M, de Vaccaro KC, Couser W, Cowie BC, Criqui MH, Cross M, Dabhadkar KC, Dahiya M, Dahodwala N, Damsere-Derry J, Danaei G, Davis A, De Leo D, Degenhardt L, Dellavalle R, Delossantos A, Denenberg J, Derrett S, Des Jarlais DC, Dharmaratne SD, Dherani M, Diaz-Torne C, Dolk H, Dorsey ER, Driscoll T, Duber H, Ebel B, Edmond K, Elbaz A, Ali SE, Erskine H, Erwin PJ, Espindola P, Ewoigbokhan SE, Farzadfar F, Feigin V, Felson DT, Ferrari A, Ferri CP, Fevre EM, Finucane MM, Flaxman S, Flood L, Foreman K, Forouzanfar MH, Fowkes FG, Franklin R, Fransen M, Freeman MK, Gabbe BJ, Gabriel SE, Gakidou E, Ganatra HA, Garcia B, Gaspari F, Gillum RF, Gmel G, Gosselin R, Grainger R, Groeger J, Guillemin F, Gunnell D, Gupta R, Haagsma J, Hagan H, Halasa YA, Hall W, Haring D, Haro JM, Harrison JE, Havmoeller R, Hay RJ, Higashi H, Hill C, Hoen B, Hoffman H, Hotez PJ, Hoy D, Huang JJ, Ibeanusi SE, Jacobsen KH, James SL, Jarvis D, Jasrasaria R, Jayaraman S, Johns N, Jonas JB, Karthikeyan G, Kassebaum N, Kawakami N, Keren A, Khoo JP, King CH, Knowlton LM, Kobusingye O, Koranteng A, Krishnamurthi R, Lalloo R, Laslett LL, Lathlean T, Leasher JL, Lee YY, Leigh J, Lim SS, Limb E, Lin JK, Lipnick M, Lipshultz SE, Liu W, Loane M, Ohno SL, Lyons R, Ma J, Mabweijano J, Maclntyre MF, Malekzadeh R, Mallinger L, Manivannan S, Marcenes W, March L, Margolis DJ, Marks GB, Marks R, Matsumori A, Matzopoulos R, Mayosi BM, McAnulty JH, McDermott MM, McGill N, McGrath J, Medina-Mora ME, Meltzer M, Mensah GA, Merriman TR, Meyer AC, Miglioli V, Miller M, Miller TR, Mitchell PB, Mocumbi AO, Moffitt TE, Mokdad AA, Monasta L, Montico M, Moradi-Lakeh M, Moran A, Morawska L, Mori R, Murdoch ME, Mwaniki MK, Naidoo K, Nair MN, Naldi L, Narayan KM, Nelson PK, Nelson RG, Nevitt MC, Newton CR, Nolte S, Norman P, Norman R, O'Donnell M, O'Hanlon S, Olives C, Omer SB, Ortblad K, Osborne R, Ozgediz D, Page A, Pahari B, Pandian JD, Rivero AP, Patten SB, Pearce N, Padilla RP, Perez-Ruiz F, Perico N, Pesudovs K, Phillips D, Phillips MR, Pierce K, Pion S, Polanczyk GV, Polinder S, Pope CA III, Popova S, Porrini E, Pourmalek F, Prince M, Pullan RL, Ramaiah KD, Ranganathan D, Razavi H, Regan M, Rehm JT, Rein DB, Remuzzi G, Richardson K, Rivara FP, Roberts T, Robinson C, De Leon FR, Ronfani L, Room R, Rosenfeld LC, Rushton L, Sacco RL, Saha S, Sampson U, Sanchez-Riera L, Sanman E, Schwebel DC, Scott JG, Segui-Gomez M, Shahraz S, Shepard DS, Shin H, Shivakoti R, Singh D, Singh GM, Singh JA, Singleton J, Sleet DA, Sliwa K, Smith E, Smith JL, Stapelberg NJ, Steer A, Steiner T, Stolk WA, Stovner LJ, Sudfeld C, Syed S, Tamburlini G, Tavakkoli M, Taylor HR, Taylor JA, Taylor WJ, Thomas B, Thomson WM, Thurston GD, Tleyjeh IM, Tonelli M, Towbin JA, Truelsen T, Tsilimbaris MK, Ubeda C, Undurraga EA, van der Werf $\mathrm{MJ}$, van Os $\mathrm{J}$, Vavilala MS, Venketasubramanian N, Wang M, Wang W, Watt K, Weatherall DJ, Weinstock MA, Weintraub R, Weisskopf MG, Weissman MM, White RA, Whiteford H, Wiersma ST, Wilkinson JD, Williams HC, Williams SR, WittE, Wolfe F, Woolf AD, Wulf S, Yeh PH, Zaidi AK, Zheng ZJ, Zonies D, Lopez AD, Murray CJ, AlMazroa MA, Memish ZA. Years lived with disability (YLDs) for 1160 sequelae of 289 diseases and injuries 1990-2010: a systematic analysis for the Global Burden of Disease Study 2010. Lancet 2012;380:2163-96. 